\title{
Representing Refugee Women: Gender and Work in Three Kenyan Camps
}

\author{
Jennifer Hyndman
}

\section{Abstrnet}

Representations of refugee women as "poor," "vulnerable," and "helpless" are often coriantures inattentive to the innowations and survioal strategies they employ. Combinad with the relatively fow images and impressions of refugee women's axperiences abailable, refugee religf workers and scholars have limited understanding of their worlds across time and space. This article aims to 1) discuss the politics, power relations, and problems of representing refugee women; 2) illustrate selected daily routines, concerns, and income-eaming strategies of Somali refugee women in Kenya; and 3) argue that the "local capacity," or indigenous skills, of this group have not been fully recognized. Astute humanitarian policy and prectice should not only promote "building local capacity" - a term often heard in relief circles today-but it should identify, mobilize, and support the kinds of local capacity identified in the Kenyan camps of Ifo, Hagadera, and Dagahaley.

\section{Pricis.}

La representation courante des femmes refugiles comme "pautres", "oulnérables" et "dtmunies" procede souvent d'une vioion caricaturale mal informée des strategies noontrices de survie que ces femmes mettent en pratique. A cause du tris petit nombred'impressions et d'images reflitant l'expicrience des femmes réfugices dont on dispose, les interoenants et les specialistes en matiere de questions de refugits ont une comprehension fort

Jenutfer Hyndman, Ph.D., is Asst. Professor of Geography, Arizona State University, West Campus, Phoenix, Arizona, USA.

The author wowld like to thank the Gender Unit at the Centrefor Refugee Studies, York University, for its fmencial support of this doctoral research in 1994-95. The research toas also funded by the Soctal Science and Resenrch Council of Canada through the doctoral fellowehip program. restreinte de l'univers de ces fermmes d travers le temps et l'espace. Le but de cet article est de: 1) aborder la question de la problematique politique, des rapports de pouvoirs, et des problemes de représentations associés aux femmes réfugiés; 2) illustrer une selection de routines quotidiennes, de problemes concrets et destratégies visant a genérer un revenu chez des femmes somaliennes réfugiées au Kenya; et 3) presenter une argumentation selon laquelle les "capacités locales", ou savoir-faire indigene, de ce groupe n'ont pas etéreconnus d leur juste valeur. Une politique et des pratiques humanitaires pertinentes ne deoraient pas seulement faire la promotion de la "constitution de capacites locales"-selon une formulation ayant presentement cours dans les milieux de l'aide aux réfugiés-mais deoraient identifier, mobiliser et donner un appui aux types de capacités locales identifíés dans les camps kenyans de Ifo, Hagadra, et Dagahaley.

In this brief article, I argue that representations of refugee women and their lives in camps must avoid the caricatures of "vulnerable," helpless victims of circumstance without losing sight of the daily struggles they face and survival strategies they employ. The paper exposes what might be thought of as indigenous relief strategies employed by refugee women in camps. "Building local capacity" is a common phrase in refugee relief circles, referring to the importance of enabling local individuals and groups to acquire the necessary resources, skills, and knowledge to perform essential functions and deliver necessary assistance when humanitarian organizations leave. While this is an important and laudable approach, it risks overlooking the existing "local capacity" and on-going strategies for survival. This article considers the daily work of Somali refugee women in three Kenyan camps. The women areengaged in complex arrangements of invisible work that constitute an importantinformal economy, easily overlooked by large-scale assessments.

Selected excerpts from twenty-five interviews conducted with refugee women in the three Dadaab camps of Ifo, Hagadera, and Dagahaley are presented below. Retelling stories recounted to me by refugee women through an interpreter to illustrate this point is, however, tricky business. By representing refugee women and their daily lives, I risk voicing over their knowledge and experience-misrepresenting them across cultural divides and differences in political status and power. By underlining their innovations, stamina, and accomplishments under arduous conditions, my story also risks saying that these women can survive whatever conditions they encounter-a dangerous conclusion in any fragile situation of human displacement. Humanitarian operations and refugee programs are heavily gendered. ${ }^{1}$ Any insight into the ways and means by which this occurs is an important addition to the paucity of writing related to refugee women.

As a feminist and a geographer, Iconducted field work in Kenya where the everyday survival strategies of refugee women living in camps constituted an important focus of my research. My own experience, first employed as a relief worker for CARE International in 1992 and then as a field officer in Somalia with UNHCR in 1993, steeped me in the intense culture of relief work. This history of working for an NGO, CARE, and UNHCR positioned me as an "insider" of sorts within the relief network in the region. At the same time, my main motivation to conduct research stemmed from observations of and reservations about refugee operations that I encountered whileemployed in the field. I was, and remain concerned that the means 


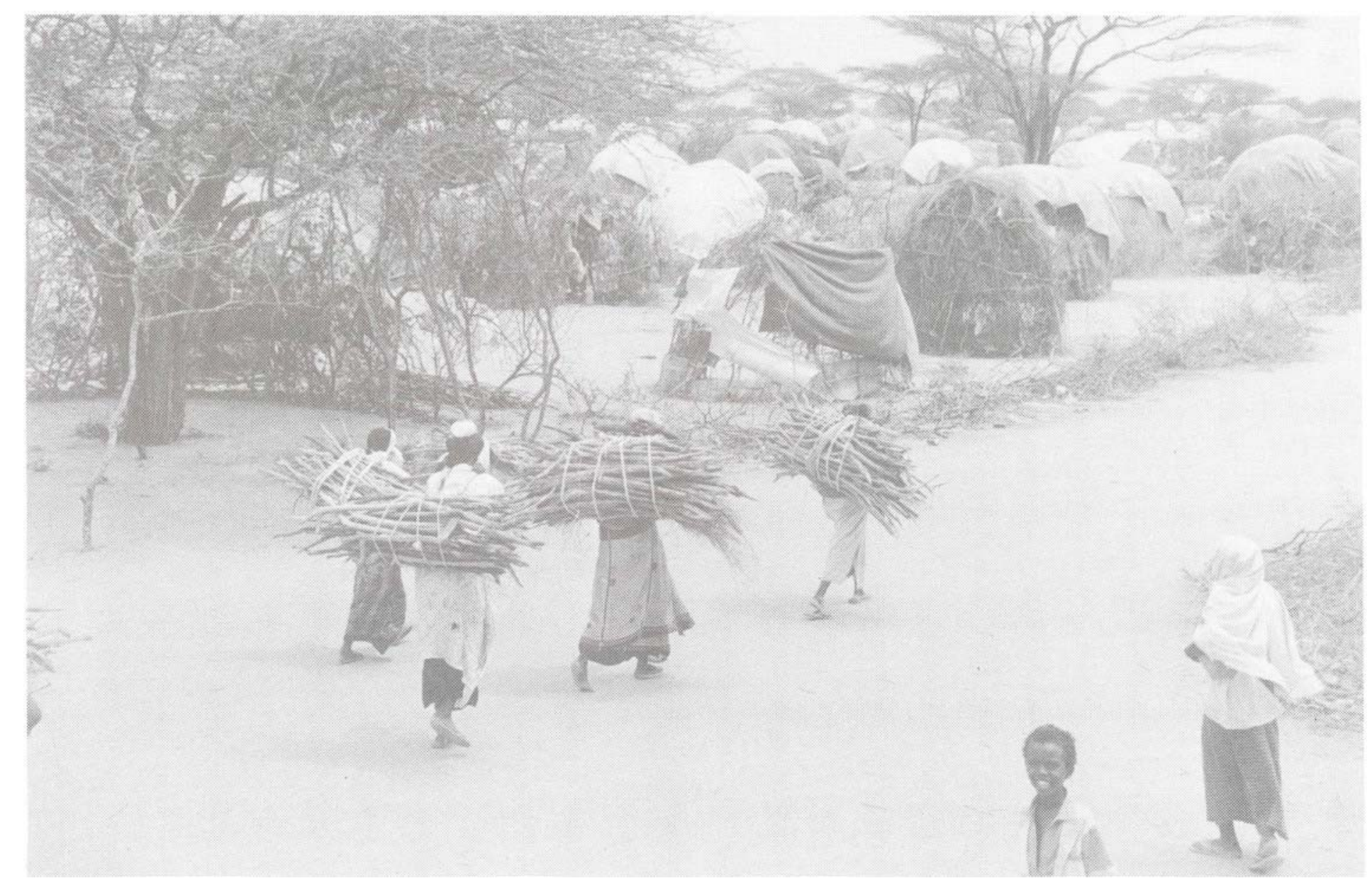

Kenya: Somali refugees in Liboi camp. To cook their food, refugees must collect fire wood. This can result in environmental damage. Photo: UNHCR/21OS2/0S.1991/B. Press

by which refugees are "managed" by humanitarian agencies reinscribe neocolonial relations of power predicated on a hierarchy of cultures in the camp, and on major asymmetries of power linked to gender and political status.2 While I was an "insider" to refugee operations having worked for two agencies, I was also critical of these operations. I was both inside and outside the project of providing humanitarian assistance.

In the camps, I found that the everyday experiences and struggles of refugee women were often invisible, inaudible, and secondary to other issues and actors in the camps. They were less likely than men to speak English; they had less access to camp jobs; and fewer opportunities to be involved in camp decision-making and consultations with relief organizations. They were, nonetheless, actively engaged in strategies to optimize their situation. Many of these refugee women were, in a different sense, both inside and outside the humanitarian project of the refugee camp. The refugee women with whom I met would be better described as left out of the project, the "abject" rather than the subjects.3While there were (and are) a number of policies in place aimed at supporting and promoting refugee women, my findings indicated that camp operations were generally inattentive to the conditions of work and home for these women.

Aware that translation is heavily invested with unequal power relations and a site for questions of representation, power, and historicity, 4 my research nonetheless attempts to incorporate some two dozen interviews with Somali refugee women in camps located in Northeastern Kenya, all of which were contingent upon the availability and skills of one translator. Sherene Razack (1996) tells of the "perils of storytelling for refuge women" in particular.5 She calls for an interrogation of the construction of subjectivity on the part of those who collect and use stories, as well as a more careful examination of how we come to know what we know given the unequal relations among groups differentiated by nationality, ethnicity, class, gender, and so on. Interviews often serve to authenticate research findings by appropriating subjugated know ledges from essentialized "native informants."6 At least as problematic as cultural appropriation is the uncomfortable realization that the interview process reinscribes the same power relations that I aimed to critique and contest from 
the outset. ${ }^{7}$ Interviews exact the same kind of authoritative performances from refugees as do the relief agencies which organize access to food, medical services, and other needs. Consent becomes almost meaningless in the wholly unequal relationship between interviewer and interviewee.

Language translation poses other difficulties in the camps. Almost all of my face-to-face interactions with refugees required a translator. Translation is a critical activity for UNHCR and all other international agencies' daily operations. Often, discussions and disagreements to which I was privy occurred solely around the issue of whose translator, "ours" or "theirs," would interpret. On one occasion, an incensed UNHCR local staff discovered that a rape incidenthad been translated to the police as "spousal assault." As Norma Alarcón (1994) notes:

The act of translating, which often introduces different concepts and perceptions, displaces and may even do violence to local knowledge through lenguage. In the process, these may be assessed as false or inauthentic.?

Refugees' displacement is both a corporeal and cultural condition. In an effort to avoid the further cultural displacement vis-a-vis the research process, I "tested" my proposed questions before commencing the interviews by having the translator-a Somali woman from the area who moved between cultures daily-review and assess whether they were conceptually and culturally "translatable."10 "Language is not a neutral medium that passes freely and easily into the private property of thespeaker's intentions; it is populated-overpopulated with the intentions of others. Expropriating, forcing it to submit to one's own intentions and accents, is a difficult and complicated process." 11 Neither translation nor the differences in cultural and professional positions of the people involved were neutral, nor were the languages employed.

Through a translator, I asked women who were randomly selected from all threecamps exactly what they had done the previous day and for what duration. I also asked about the economy of the household, the adequacy of food rations distributed by CARE, and the means by which the family covered any deficits. In what ways are pattems of mobility constituted through gender relations defined by social organizhtion, access to resounces, and political status? While the brief geographical stories offered here are imperfect "sketches" of refugee women's work, my intent is to document time-space constraints and strategies which women employ under these conditions. ${ }^{12}$ The stereotypical depiction of refugee women as vilinerableand helpless is smashed by many of these stories.

The selection of responses presented here serves to illustrate how space is negotiated during a given day and some of the activities and income-earning strategies women employed. I avoided asking questions that the United $\mathrm{Na-}$ tions High Commissioner for Refugees (UNHCR) and the non-governmental organizations (NGOs) often posed; such as household size and composition, so that I might distinguish my research from the monitoring roles of administering agencies. While one cost of this approach is the absence of biographical detail with respect to refugee families, the purpose of my study was not to develop a description of their households but to understand the influence of the humanitarian hgencies on their lives. My questions forused on the ways that UNHCR and NGOs affected the routines of refugee women, in terms of camp layout, organization, and supplies provided to them. All of the refugee women interviewed were athome when approached by the interpreter and $\mathrm{my}$ self.

The texts presented are blased on the verbatim translations of the interpreter, and as such, are presented in the third person. This strategy of tepresentation-one which inserts both the interpreter and my own cultural distance from the interviewee-is a deliberate effort to render visible, transparent, and problematic the process of translation and the power relations interviews involve.

\section{Interoiew \#1}

(Ifo Camp, Section A6, young Somali woman with baby.) She rises at five to prepare tea and breakfast, tea alone yesterday because there was no wheat flour in the last food distribution. After an hour of washing clothes and children, she grinds and mills sorghum for lunch. Whilelunch is cooking, she goes to look for firewood which takes about three hours. She eats lunch with the family and relaxes until three-thirty when she goes to look for water. She returns two hours later and starts supper which is eaten between seven and seven-thirty. Then they visit as a family and go to sleep between eightthirty and nine.

\section{Interoiew \#2}

(Hagadera Camp, Section D3, young Somali woman with baby: the woman is grinding sorghum into flour upon our arrival.) She wakes up at six. Until nine, she is preparing breakfast, washing utensils, and cleaning the compound-sweeping and such. Between nine and ten, she goes for water. From ten to twelve, she grinds sorghum (as she is now). From twelve to two, she prepares, cooks, and eats lunch. Then she goes for firewood until four. At four, she goes back home to prepare tea and sorghum again until six. By seventhirty, supper is eaten and finished. She is sleeping by nine.

It is worth noting that sorghum, like whole grain wheat, is one of the most labour-intensive foods to prepare because it has to be ground and milled by hand. In the camps among Somalian refugees, this work is a female responsibility and, as these excerpts suggest, consumes a large part of daily routine. Rice is both the easiest to cook and the most popular staple among Somalis. It has also become a rare ration during food distributions in the Dadaab camps. Both staples do, of course, require cooking with water and wood which are also collected by women.

\section{Interview \#3}

(Dagahaley Camp, Section F0, young Somali woman with baby.) Sheawak- 
ens at six and has her prayers first. She then prepares tea for the children, washes the utensils, cleans the house and bathes the children until about nine. She collects water, and at about nine-thirty, starts the process of preparing sorghum for the noon meal. At noon, she begins cooking for about an hour. Everyone eats at two and then rests. After three, the same grinding of sorghum for the evening meal begins. More water is fetched, and she cooks dinner. The children are fed by eight. She then visits with the neighbours for a while and goes to sleep by nine.

Sometimes her husband collects firewood to sell, but it is dangerous because bandits rob and sometimes attack people collecting firewood. This woman is part of a group of women formed in order to meet additional income needs. In a group of about five, each woman contributes an equal portion of her ration after a distribution. The total sum is sold at the market and the money is given to one of the women. The system rotates so that each woman eventually benefits by having access to credit.13

An informal economy of trade is rendered visible here. The credit afforded these women allows them to buy household items such as tea, footwear, and clothing which are not generally provided for by relief agencies. Other items, such as cooking oil, are often needed to supplement the supply distributed by CARE in the camps. Women are largely responsible for maintaining the household and earning additional income to meet other needs.

Where are the men in this picture? Given the social organization of Somali families in such a way that one man may have more than one wife, many households are led by women. One cannot speak of gender divisions of work, however, without accounting for men's activities in the camps. A requestformore information to fill this gap by UNHCR staff in Nairobi and Dadaab was met with this response:

It's not the same for all groups of men. The Somali men are different from the Sudanese, and so on. As far as the Dadaab camps go, a lot of men are just wandering around meeting

Refuge, Vol. 17, No.1 (February 1998) other men. They talk politics and what have you in the shade under the tree or they go to the local cafe to rest for a coffee and to play some games (chess, cards, and loca games). Some men have jobs with CARE and other NGOs.14

Men's absence from the homes at which the interviews took place was which the interviews took place was
evident. Their daily activities were, as this transcript suggests, more difficult to trace. The following interviews illustrate the geographies of refugee women who did not appear to have much active male support in their households.

\section{Interview \#4}

(Ifo Camp, Section A6, a young Somali woman.) She is awake by five, lights the fire, and makes tea and food for the family. By seven, she leaves to look for firewood, which takes about three hours, and then takes the wood to the market to sell. She returns home by noon, prepares lunch, and takes a bit of rest until three when she goes to fetch water.

This also takes three hours because there is a queue. Supper is prepared and the family eats by seven. Up until about nine, she talks with he neighbours who live within the same fenced compound. Then, she is ready for sleeping.

The official ration is not enough. She sells firewood to buy extra food.

\section{Interview \#5}

(IfoCamp, Section A6, an old woman. The interview format varies somewhat from the others because the woman thought she was too old to be relevant to the questions posed.) This woman has two grandsons who are orphans. She has a ration card for a family of five. She doesn't go to the market (to earn extra money). She does washing and cooking though not to the same extent as younge women. Her neighbours collect firewood in bulk and give her some. She als receives help from the AlHaramein (an NGO nearby) with her firewood supply. price is very low.

While anecdotal, interviews such as this one pointed to informal support systems for households at a disadvantage. Refugees living in the same area sometimes shared water and firewood when they were in scarce supply. NGOs like AI-Haramein and CARE make some effort to identify vulnerable refugees and assist them where possible.

\section{Interview \#6}

(Dagahaley Camp, Section D4, young woman with baby.) She rises at six. She has a maid who cooks in the kitchen. Yesterday, someone-the husband of a pregnant womancame to her house and asked her to come to Section CS where the pregnantwomanlived. (She has a job with the French medical NGO as a traditional birth attendant, or TBA). She stayed there until nine, after which she went for help. A vehicle was called to take the woman to the hospital where she gave birth. The traditional birth attendant stayed with the new mother until eleven when she returned to the house. She rested, had lunch, and atthree, began to build a new tllklll (hut) which took about an hour. She built another one today, the one in which we're sitting. They are for the coming hot season and for Ramadhan. At four, she returned to work, stayed until six, and then came home. She bathed herself and her kids while the maid cooked. The family ate supper and stayed around the house. At eight, they slept.

While refugee women with jobs are few, their earned income affords them "extras," such as the services of a "maid" in this example. According to the interpreter with whom I conducted the interview, domestic help is common among more affluent families in Somali society. Usually, it is young unmarried women who work and live with a family in exchange for room and board and a small stipend.

\section{Interview \#7}

(Dagahaley Camp, Section DS, a Bantu-Somalian woman.) She woke up at six in the morning, made breakfast and cleaned house until eightthirty. Then she wentforwater which took two hours, until tenthirty. Afterwards, she went to the market to buy wheat flour in order to make a 
local bread which shesells. Returning at noon, she made lunch and finished enting. Then she went back for water, which took from two to six in the evening, but she came back emptyhanded. (I asked why the water problem? She said the population is dense there, and the water pressure very low). She made supper for the family, arranged the beds for the children, and afterwards slept.

The considerable time and effort required to collect water and firewood is exacerbated by population concentration in the desert-based camps. Decentralized water taps are located within the camp perimeter at a distance not usually more than 500 meters from any given refugee tukul (hut). Nonetheless, lines can be long and pressure poor at some distribution points. Firewood is often sold in the local refugee camp markets, but must otherwisebecollected well beyond the boundaries of the camps. Refugee women cover up to fifteen kilometres on a single journey to gather firewood. ${ }^{15}$

Just as industrial geography and sociology once spoke of "cathedrals in the desert," referring to culturally, economically, and geographically inappropriate projects established in the name of "development," refugee camps are desert cities similarly unsuited to highly concentrated human populations. While a sizable aquifer runs below the desert floor in the Dadaab area where the camps are situated, providing ample supplies of water and wood for 110,000 visiting refugees is an obvious environmental challenge. What is less obvious is the shift in demand for these commodities based on the kinds of external food aid imported. Both the Somali Kenyans and many of the Somali refugees living in the Dadaab area have alargely nomadicbackground based on economies of livestock-camels and cattle, in particular. Meat and milk from these sources comprise the staple foods of the population, the latter of which requires neither wood nor water to prepare. The arrival and preparation of large amounts of wheat, rice, corn-soy blend, dried kidney beans, and other non-perishable food aid from other oversupplied regions of the world to camps in Kenya pose serious environmental questions. Because each of these commodities requires considerable amounts of water and wood to prepare, the paucity of these resources is exacerbated and the daily collection of them becomes increasingly difficult for refugee women. ${ }^{16}$

\section{Interview \#8}

(Hagadera Camp, Section E2, a Bantu-Somalian woman with a newborn baby; the woman is standing pounding sorghum as we arrive.) She wakes up at seven. From seven to eight, she prepares breakfast and the family eats it. Between eight and nine, she goes for water; from nine to twelve she prepares sorghum, crushing it, making it into powder. Between twelve and two, she cooks and eats lunch. From two to three, she went [sic] back for water; from four $o^{\prime}$ clock is supper preparation and bathing of children until five. By six, supper is ready and she makes sure the little ones are fed because they go tosleep earlier. Up until seven-thirty, the elder people have supper. From seven-thirty until eight, she chats with the children and her people (I didn't clarify the possessive adjective here but assume it means other Bantu-Somalians with whom she shares a fenced compound). She goes to sleep between eight and nine.

To earn extra money, she begins some days by fetching and selling jerry cans of water to other households. She usually sells six cans (20 litres each) at 3 shillings each in a morning. This gives her enough money (U.S. \$0.33) to buy someone else's bulk firewood off a donkey cart which she then sells in smaller bundles in the market.

This elaborate income-generating arrangement suggests spatial constraints and possibly security considerations. Rather than stray far from the camp to collect her own firewood before sunrise and with children in tow, this woman hauls water closer to home to earn the seed money requited to buy bulk firewood from someone else. The tiny amounts of money accrued in each exchange are part of an informal economy which is constituted through the spatially circumscribed and artifi- cially-endowed formal economy of the camp. The sale of refugee labour and of donated commodities provide the basis for trade in the camps. Based on the collection of water and wood, and the selling of food aid, ad hoc markets which carry a range of provisions-cigarettes, spices, tea, candies, and camel milk among them-have been established in all of the camps. Refugee women's work is not simply a struggle to meet multiple household and income demands. While work is convoluted by the spatial segregation and organization of the camps, refugee women employ elaborate strategies tomake ends meet. Creditschemes and labour-intensive entrepreneurial activities of various kinds are evidence of a vital informal economy.

Somali cultural practices code household work as a women's responsibility, but women's work cannot simplybe reduced to the gendered division of labour. One can describe the temporary urban spaces of the desert camps as expressions of an "supra-local order," characterized by foreign foodstuffs and a layout that suits the administrators and suppliers at least as much as the refugees. It at once exacerbates the burden of work that women do and reinscribes their routines. What becomes clear from these selected geographies of refugee work is that a significant amount of time is spent performing tasks that allow for basic subsistence and survival in the camps. Dry foodstuffs generate a high demand for wood and water amid a concentrated population. The nomadic practices of many Somalis, including their reliance on meat and milk which requires less wood and water, are not incorporated into the organization of the camps.

What do these excerpts from stories of refugee women tell us? The survival strategies and cooperative ventures that humanitarian organizations aim to put in place are, in some cases, already there. There is a clear need for trade and a small informal cash economy in order to access items not distributed in refugee rations. A complex economy of both formal and informal exchange takes place within the camps. And yet the commodities available are not always 
appropriate, culturally or environmentally speaking. The testimony of these refugee women suggests an on-going concern and awareness with the material conditions ofliving in the camps, as much as the political nature of their displacement. ..

\section{Notes}

1. Wenona Giles, "Aid Recipients or Citizens?: Canada's Role in Managing the Gender Relations of Forced Migration," in Development and Diaspora: The Gender Relations of Refugee Experience, edited by W. Giles, H. Moussa, P. Van Esterik (Dundas, Ontario: Artemis Enterprises, 1996)

2. Jennifer Hyndman, "Border Crossings," in Antipode 29, no. 2 (1997): 149-76.

3. Judith Butler, Bodies that Matter: On the Discursive Limits of 'Sex' (New York: Routledge, 1993).

4. Tejaswini Niranjana, Siting Translation: History, Post-Structuralism, and the Colonial Context (Berkeley: UniversityofCalifomia Press, 1992).

5. Sherene Razack, "The Perils of Storytelling for Refugee Women," in Development and Diaspora: The Gender Relations of Diaspora: The Gender Relations of
Refugee Experience, edited by W. Giles, H. Refugee Experience, edited by W. Giles, H.
Moussa, P. Van Esterik (Dundas, Ontario: Moussa, P . Van Esterik (Dundas, O
Artemis Enterprises, 1996), 271-89.

6. Donna Haraway, "Situated Knowledg,es" in Simians, Cyborgs, and Women: The Reinvention of Nature (New York: Routledge, 1991), 183-201.

7. Helene Moussa, Storm and Sanctuary: The Journey of Ethiopian and Eritrean Refugee Women (Dundas, Ontario: Artemis, 1993). Helene Moussa's research with Eritrean and Ethiopian refugees. addresses the "politics of research" and provided important background for my interviews with refugees. Her positioning as a researcher, however, differs significantly from my own. Her project of tracing the journeys of sixteen Eritrean and Ethiopian women from their homes in the Horn of Africa to Canada focuses on the experience of the women as refugees, rather than on UNHCR's strategies to manage refugee populations.

8. TheexceptiontothismaybeAI-Haramein, the staff of whom speak Arabic from which many Somali words are derived. However, only a few (male) elders and educated Somalis are conversant in the language.

9. Norma Alarc6n, "Traddutora, Traditora: A Paradigmatic Figure of Chicana Feminism," in Scattered Hegemonies, edited by I. Grewal and C. Kaplan (Minneapolis: Minnesota University Press, 1994), 113.

10. The articles included in Scattered Hegemonies, edited by I. Grewal and C. Kaplan (Minneapolis: Minnesota University Press, 1994) were the primary source sity Press, 1994) were the primary source
of provocation at that time. The work of of provocation at that time. The work of
Tejaswini Niranjana is also helpful here: Siting Translation: History, PostStructuralism, and the Colonial Context (Berkeley: University of California Press, 1992).

11. Mikhail Bakhtin cited in Norma Alarc6n, 1994, op. cit., 119

12. Isabel Dyck, "Space, Time, and Renegotiating Motherhood: An Exploration of the Domestic Workplace," in Environmentand Planning D: Society and Space, no. 8, 1990. See also Suzanne Mackenzie, "Restructuring the Relations ofW ork and Life: women as Environmental Actors, Feminism as Geographical Analysis" in Remaking Human Geography, edited by A. Remaking Human Geography, edited by A. Kobayashi and S. Mackenzie (London: Unwin Hyman, 1989),4D-61, and Geraldine Pratt and Susan Hanson,
"Women and Work Across the Life Course: Moving Beyond

Essentialism," in Full Circles: Geographies of

Women over the Life Course, edited by C. Katz and J. Monk (New York: Routledge, 1993),27-54. Doreen Massey's work on the "politics of mobility" also serves as corrective to any assumption of absolute space or equality of movement among people. See D. Massey "Power-Geometry and a Progressive Sense of Place," in Mapping the Futures: Local Cultures, Global Change, edited by J. Bird, B. Curtis, T. Putnam, G. Robertson, and L. Tickner, (New York: Routledge, 1993),59-69.

13. To calculate the amount of credit made To calculate the amount of credit made available on a rotating basis, one might make the following assumptions: each of
the five women has a family size of five. Each person is allotted $0.5 \mathrm{~kg}$ of grain per day, so that a 15 day distribution would include $7.5 \mathrm{~kg}$ per person and $37.5 \mathrm{~kg}$ per family. If each woman contributed one fifth of her total grain allocation $(7.5 \mathrm{~kg})$, the collective amount would equal $37.5 \mathrm{~kg}$. The price wheat flour, the most $.5 \mathrm{~kg}$. The price wheat flow, the most common grain staple, ranged from 3 to 5 Kenyan shillings (KSh) per kilo. This represents a total credit each time of between $112.5 \mathrm{KSh}$ and $187.5 \mathrm{KSh}$, the equivalent of U.S. \$2.00-3.40.

14. E-mail transcript from UNHCRin Nairobi, June 7, 1996.

15. UNHCR, The State of the World's Refugees: In

Search of Solutions (Oxford and New York: Oxford University Press, 1995)

16. In Malawi, the wood consumed by refugees was considerable: some 20,000 hectares of forest per year. In Nepal, Bhutanese refugees used 400 kilos per capita of fuelwood per year. UNHCR provided kerosene stoves and fuel in this case; see UNHCR, 1995, op. cit. While relative UnHer, expensive fuel alternatives have been employed, major changes in the refugee food basket-as a major source of the problemhavenot been entertained. UNHCR has a number of nutritionists on staff to ensure that foodstuffs provide sufficient nourishment, but the agency relies on the UN Wodd Food Program (WFP) to collect donations for the camps. 0

\section{Breaking Ground:}

\section{The 1956 Hungarian Immigration to Canada \\ Edited by Robert $\mathrm{H}$. Keyserlingk \\ Toronto: York Lanes Press, 1993, ISBN 1-55014-232-1, 117 pages, $\$ 6.99$}

This book is a collection of personal and archival-based memories on the selection, transport and settlement of about 40,000 Hungarian refugees in Canada in one year. It is a source of primary record as well as scholarly reflection on one of the most significant refugee movements to Canada after World War II-the 1956 Hungarian refugee movement.

Based on papers that were presented at a 1990 conference, the authors touch on the unique political, administrative and settlement features of this movement. The resulting work, edited by Professor Keyserlingk, is a unique mix of personal reminiscences and academic scholarship.

Available from the Centrefor Refugee Studies.

Refuge, Vol. 17, No.1 (February 1998) 